P-ISSN 2580 - 7781

E-ISSN $2615-3238$

\title{
RANCANG BANGUN SISTEM INFORMASI KONSELING REMAJA PADA DINAS PENGENDALIAN PENDUDUK DAN KELUARGA BERENCANA DENGAN METODE WATERFALL
}

\section{DESIGN OF INFORMATION SYSTEMS FOR ADOLESCENT COUNSELING IN THE DEPARTMENT OF POPULATION AND FAMILY CONTROL WITH WATERFALL METHOD}

\author{
Robi Sopandi ${ }^{1)}$, Muhammad Tabrani ${ }^{2)}$, Abdussomad ${ }^{3)}$ \\ Program Studi Teknik Informatika Universitas Nusa Mandiri \\ Program Studi Sistem Informasi/Program Sistem Informasi AkuntansiUniversitas Bina \\ Sarana Informatika \\ ${ }^{1}$ Email: robi.rbs@nusamandiri.ac.id
}

\begin{abstract}
ABSTRAK
Badan Koordinasi Keluarga Berencana Nasional (BKKBN) menunjukan data bahwa proporsi remaja usia 15-19 tahun yang sudah melahirkan dan hamil anak pertama naik dari 8,5\% (SDKI 2007) menjadi 9,5\% (SDKI 2012). Laporan review tahunan Unicef 2014 menguatkan data tersebut dengan mengungkapkan bahwa satu dari empat perempuan di Indonesia menikah sebelum berumur 18 tahun. Maka dari itu, diberlakukannya sosialisasi kegiatan yang menjadi salah satu program dari PIK-R (Pusat Informasi Konseling Remaja) dengan memberikan akses informasi ataupun konseling tentang permasalahan remaja yang cukup dan benar tentang penyiapan kehidupan berkeluarga bagi remaja/mahasiswa. Berdasarkan hasil penelitian sebelumnya, maka penulis melakukan observasi pada kantor Dinas Pengendalian Penduduk dan Keluarga Berencana Kabupaten Karawang, mengenai prosedur-prosedur yang terdapat didalamnya masih belum terkomputerisasi sehingga dalam menjalankan sosialisasi kegiatan masih ditemui kesalahan-kesalahan seperti kegiatan yang tidak sesuai dengan jadwal yang sudah ditentukan, Koordinator SATPEL Per-Kecamatan yang masih berdatangan ke kantor DPPKB Kabupaten untuk mengambil undangan sosialisasi kegiatan sekaligus memberikan data-data PIK-R kepada staff admin bidang Pembangunan Ketahanan Keluarga, penelitian ini mengambil contoh objek rancang bangun sistem informasi konseling remaja dengan berbasis web menggunakan metode waterfall karena dengan metode ini lebih mudah dalam merancang sebuah website
\end{abstract}

Kata kunci: Konseling, Waterfall, Website.

\begin{abstract}
The National Family Planning Coordinating Board (BKKBN) shows that the proportion of adolescents aged 15-19 who have given birth and are pregnant with their first child has increased from 8.5\% (2007 IDHS) to 9.5\% (2012 IDHS). The 2014 Unicef annual review report corroborates this data by revealing that one in four women in Indonesia is married before the age of 18. Therefore, the implementation of socialization activities which are one of the programs of the PIK-R (Youth Counseling Information Center) by providing adequate and correct access to information or counseling about adolescent problems regarding the preparation of family life for adolescents / students. Based on the results of previous
\end{abstract}


P-ISSN $2580-7781$

E-ISSN 2615 - 3238

research, the authors made observations at the Office of Population Control and Family Planning in Karawang Regency, regarding the procedures contained therein are still not computerized so that in carrying out the socialization of activities there are still errors such as activities that are not according to the predetermined schedule. The Per-District SATPEL Coordinator who is still coming to the district DPPKB office to take invitations to socialize activities as well as provide PIK-R data to the admin staff in the field of Family Resilience Development. Waterfall because with this method it is easier to design a website.

Keywords: Counseling, Waterfall, Website.

\section{PENDAHULUAN}

Pusat Informasi dan Konseling Remaja (PIK-R) merupakan suatu wadah kegiatan program Badan Kependudukan dan Keluarga Berencana Nasional (BKKBN) yang dikelola dari, oleh dan untuk remaja guna memberikan pelayanan informasi dan konseling tentang perencanaan kehidupan berkeluarga bagi remaja serta kegiatan-kegiatan penunjang lainnya. Berdasarkan data Badan Kependudukan dan Keluarga Berencana $(\mathrm{BKKBN})$, pada saat ini PIK Remaja berjumlah sekitar 23.579 tersebar di 34 Provinsi yang diharapkan menjadi wadah bagi remaja untuk berkempul, berbagi cerita bekreatif dan saling tukas informasi.

PIK Remaja dikembangkan bisa melalui jalur pendidikan dan masyarakat, jalur pendidikan meliputi sekolah perguruan tinggi, dan pesantren. Sedangkan di jalur masyarakat diantaranya melalui organisasi kepemudaan, organisasi keagamaan, dan komunitas remaja. Kedua jalur tersebut akan membantu mendekatkan akses remaja terhadap informasi GenRe khususnya Kesehatan Reproduksi Remaja, penyiapan kehidupan berkeluarga bagi remaja, life skill, kependudukan dan pembangunan keluarga. Berdasarkan wawancara yang telah dilakukan dengan Kepala Bidang Pendayagunaan PKB, PLKB, dan IMP, maka penulis melakukan observasi pada kantor Dinas Pengendalian Penduduk dan Keluarga Berencana Kabupaten Karawang mengenai prosedur-prosedur yang terdapat didalamnya masih belum terkomputerisasi sehingga dalam menjalankan sosialisasi kegiatan masih ditemui kesalahan-kesalahan seperti penginformasian. Sosialisasi kegiatan serta pendaftaran dan pelaksanaan yang masih manual dengan tingkat keamanan masih rentan, sehingga hasil yang diperoleh kurang cepat, tepat, dan akurat. 
P-ISSN 2580 - 7781

E-ISSN 2615 - 3238

Dari permasalahan yang telah penulis paparkan diatas maka dalampenyusunan penelitian ini penulis mengambil judul.“ Rancang Bangun Sistem Informasi Konseling Remaja Pada Dinas Pengendalian Penduduk Dan Keluarga Berencana Dengan Metode Waterfall”.

\section{METODE PENELITIAN}

Metode pengembangan perangkat lunak yang digunakan dalam merancang web forum sosialisasi kegiatan ini adalah model Air Terjun (Waterfall). Adapun tahap dalam model air terjun menurut Rachman, Beny, \& Fernando, 2017 dalam (Agustian, 2019) sebagai berikut:

\section{Analisa Kebutuhan Perangkat Lunak}

Proses pengumpulan kebutuhan dilakukan secara intensif untuk mespesifikasikan kebutuhan perangkat lunak agar dapat dipahami perangkat lunak seperti apa yang dibutuhkan oleh user spesifikasi kebutuhan perangkat lunak pada tahap ini perlu untuk didokumentasikan.

2. Desain

Desain perangkat lunak adalah proses multilangkah yang fokus pada desain pembuatan program perangkat lunak termasuk struktur data, arsitektur perangkat lunak, representasi antarmuka, dan prosedur pengkodean. Tahap ini mentranslansi kebutuhan perangkat lunak dari tahap analisis kebutuhan ke representasi desain agar dapat diimplementasikan menjadi program pada tahap selanjutnya. Desain perangkat lunak yang dihasilkan pada tahapan ini juga perlu didokumentasikan.

3. Pembuatan Kode Program

Desain harus ditranslasikan kedalam program perangkat lunak. Hasil dari tahapan ini adalah program computer sesuai dengan desain yang telah dibuat pada tahap desain.

4. Pengujian

Pengujian fokus pada perangkat lunak dari segi lojik dan fungsional, dan memastikan bahwa semua bagian sudah diuji. Hal ini dilakukan untuk meminimalisir 
P-ISSN 2580 - 7781

E-ISSN 2615 - 3238

kesalahan (error) dan memastikan keluaran yang dihasilkan sesuai dengan yang diinginkan.

5. Pendukung (support) atau pemeliharaan (maintenance)

Tidak menutup kemungkinan sebuah perangkat lunak mengalami perubahan ketika sudah dikirimkan ke user. Perubahan bisa terjadi karena adanya kesalahan yang muncul dan harus beradaptasi dengan linngkungan baru. Tahap pendukung atau pemeliharaan dapat mengulangi proses pengembangan mulai dari analisis spesifikasi untuk perubahan perangkat lunak yang sudah ada. Tetapi tidak untuk membuat perangkat lunak baru.

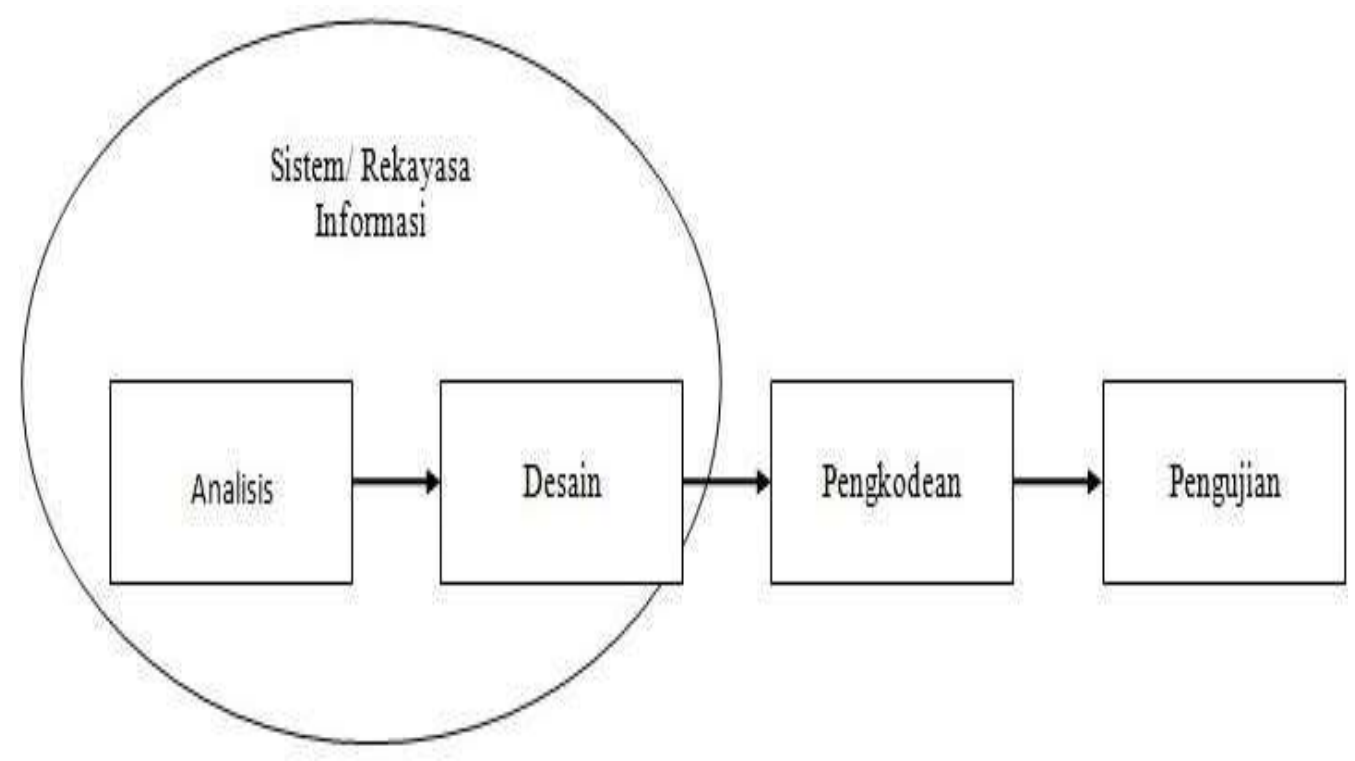

Gambar 1. Diagram waterffal

Sumber: (Sukamto \& Shalahuddin, 2014)

Teknik pengumpulan data yang digunakan dalam penelitian ini adalah :

1. Observasi

Observasi menurut Sugiyono (Sugiyono, 2016) meliputi "suatu proses yang kompleks, suatu proses yang tersusun dari pembagai proses biologis dan psikologis". Penulis melakukan observasi secara langsung ke bagian Bidang PKK (Pembangunan Ketahanan Keluarga) terhadap sistem sosialisasi PIK-R/M pada Dinas Pengendalian 
P-ISSN 2580 - 7781

E-ISSN 2615 - 3238

Penduduk Keluarga Berencana Kabupaten Karawang untuk mendapatkan data-data yang dibutuhkan dengan akurat, cepat dan tepat.

2. Wawancara

Penulis melakukan proses tanya jawab kepada Kepala Bidang maupun Kepala Seksi Bidang Pembangunan Ketahanan Keluarga mengenai program PIK Remaja/mahasiswa mengenai sosialisasi kegiatan program GenRe dan kelompok PIK-R/M pada Dinas Pengendalian Penduduk Keluarga dan Berencana Kabupaten Karawang guna untuk mendapatkan informasi yang dibutuhkan.

\section{Studi Pustaka}

Menurut Nazir (Nazir, 2011) meliputi "memperoleh informasi dari penelitian terdahulu harus dikerjakan, tanpa memperdulikan apakah sebuah penelitian menggunakan data primer atau data sekunder". Pengambilan data-data dari buku maupun internet guna mendapatkan referensi tambahan dalam penyusunan laporan ini untuk mendapatkan data skunder yang akan digunakan sebagai landasan perbandingan antara teori dengan prakteknya di lapangan. Data skunder melalui metode ini diperoleh dengan cara mengambil informasi-informasi penting mengenai permasalahan yang dibahas dengan jelas dari buku-buku referensi, atau browsing di internet (website), Jurnal dan literatur-literatur.

\section{HASIL DAN PEMBAHASAN PENELITIAN}

1. Analisa Kebutuhan Sistem

Adapun spesifikasi kebutuhan pengguna yang akan diterapkan pada sistem ini berdasarkan masing-masing pengguna adalah sebagai berikut:

a. Web Anggota

1) Login Anggota

2) Anggota dapat melakukan pendaftaran anggota konseling

3) Anggota dapat melihat materi konseling

4) Anggota dapat melihat video konseling 
P-ISSN 2580 - 7781

E-ISSN 2615 - 3238

5) Anggota dapat mengerjakan dan melihat uji wawasan

b. Web Administrator

1) Administrator dapat melakukan login

2) Administrator dapat mengakses halaman utama

3) Administrator dapat mengelola data anggota

4) Administrator dapat mengelola data konseling

5) Administrator dapat mengelola uji wawasan

6) Administrator dapat mengelola laporan

\section{Entity Relationship Diagram}

Entity Relationship Diagram (ERD) adalah suatu diagram yang digunakan untuk merancang suatu basis data, dipergunakan untuk memperlihatkan hubungan atau relasi antar entitas atau objek yang terlihat beserta atributnya.

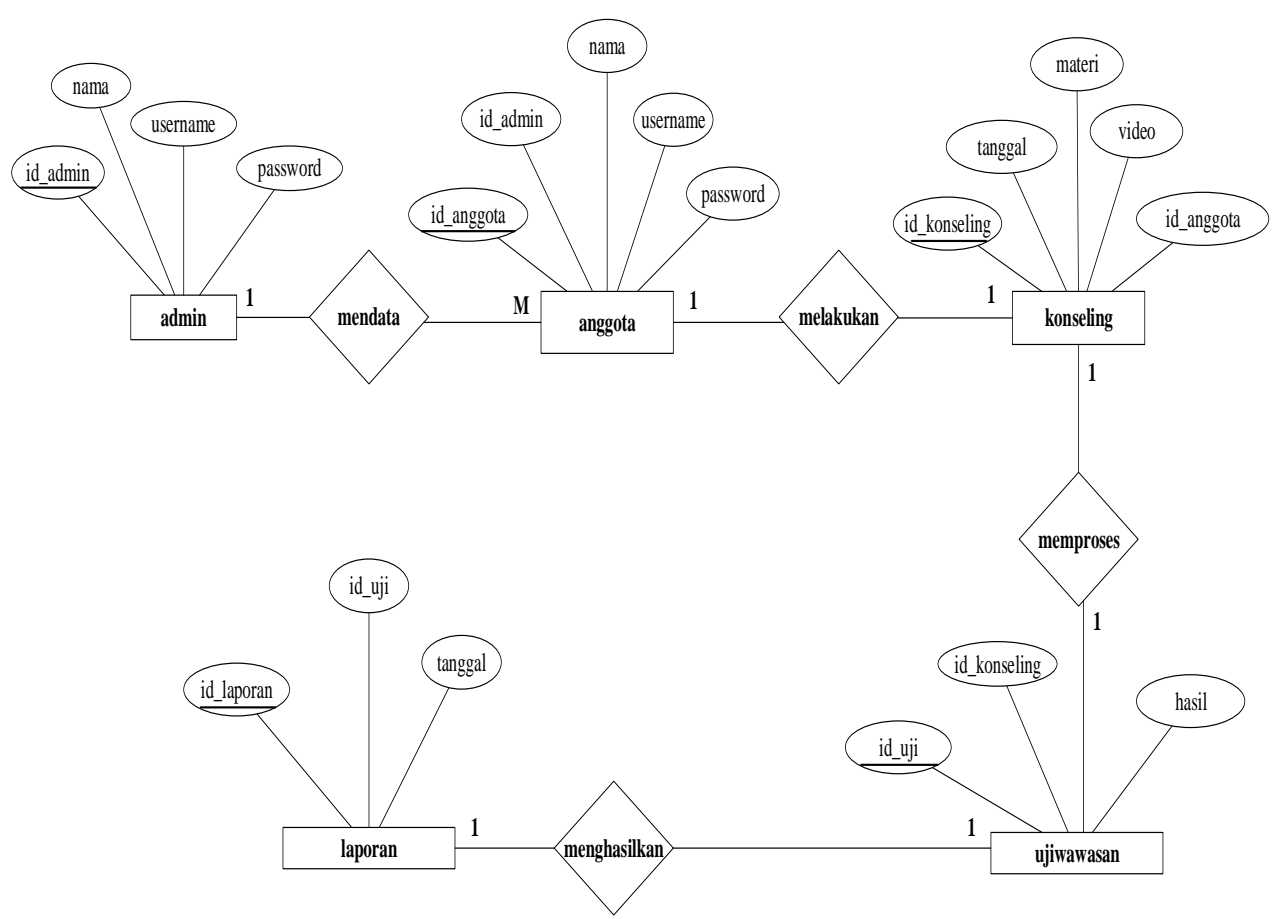

Gambar 2. Entity relationship diagram 
P-ISSN 2580 - 7781

E-ISSN 2615 - 3238

\section{Sequence Diagram}

Kegunaannya untuk menunjukkan rangkaian pesan yang dikirim antara object juga interaksi antara object. Sesuatu yang terjadi pada titik tertentu dalam eksekusi sistem.

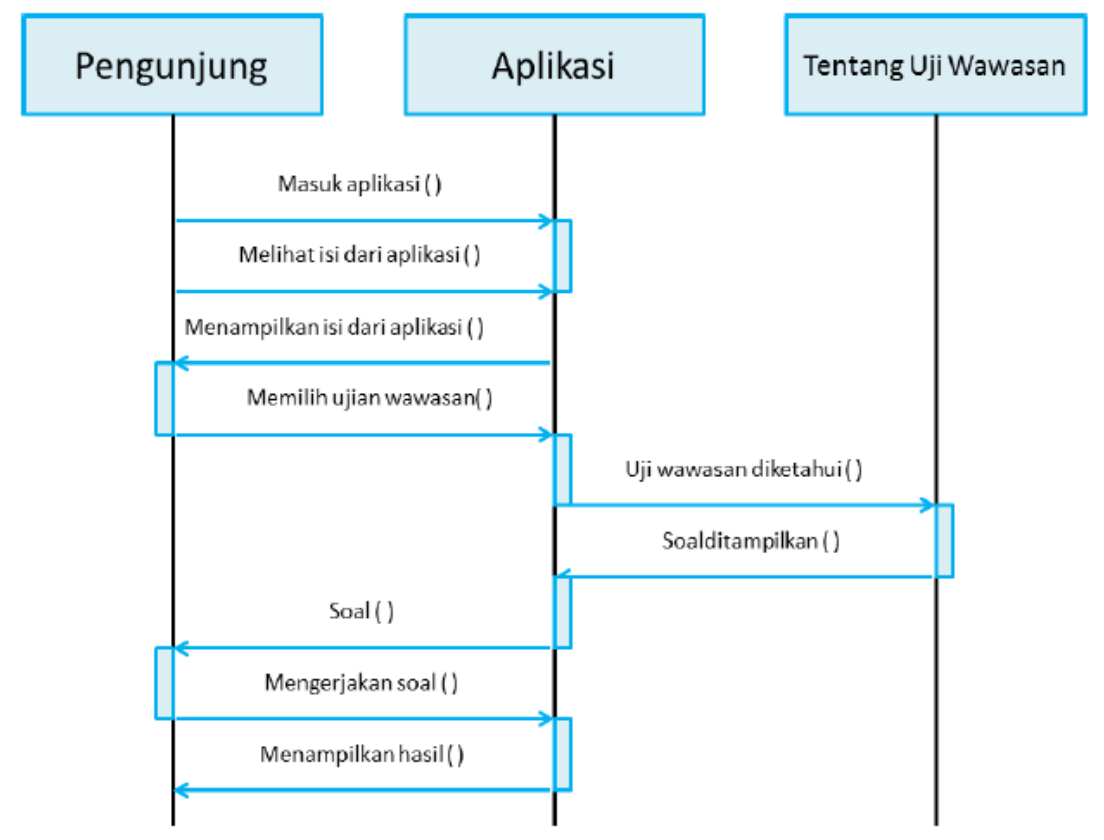

Gambar 3. Sequence Diagram 
P-ISSN 2580 - 7781

E-ISSN 2615 - 3238

\section{Logical Record Structure}

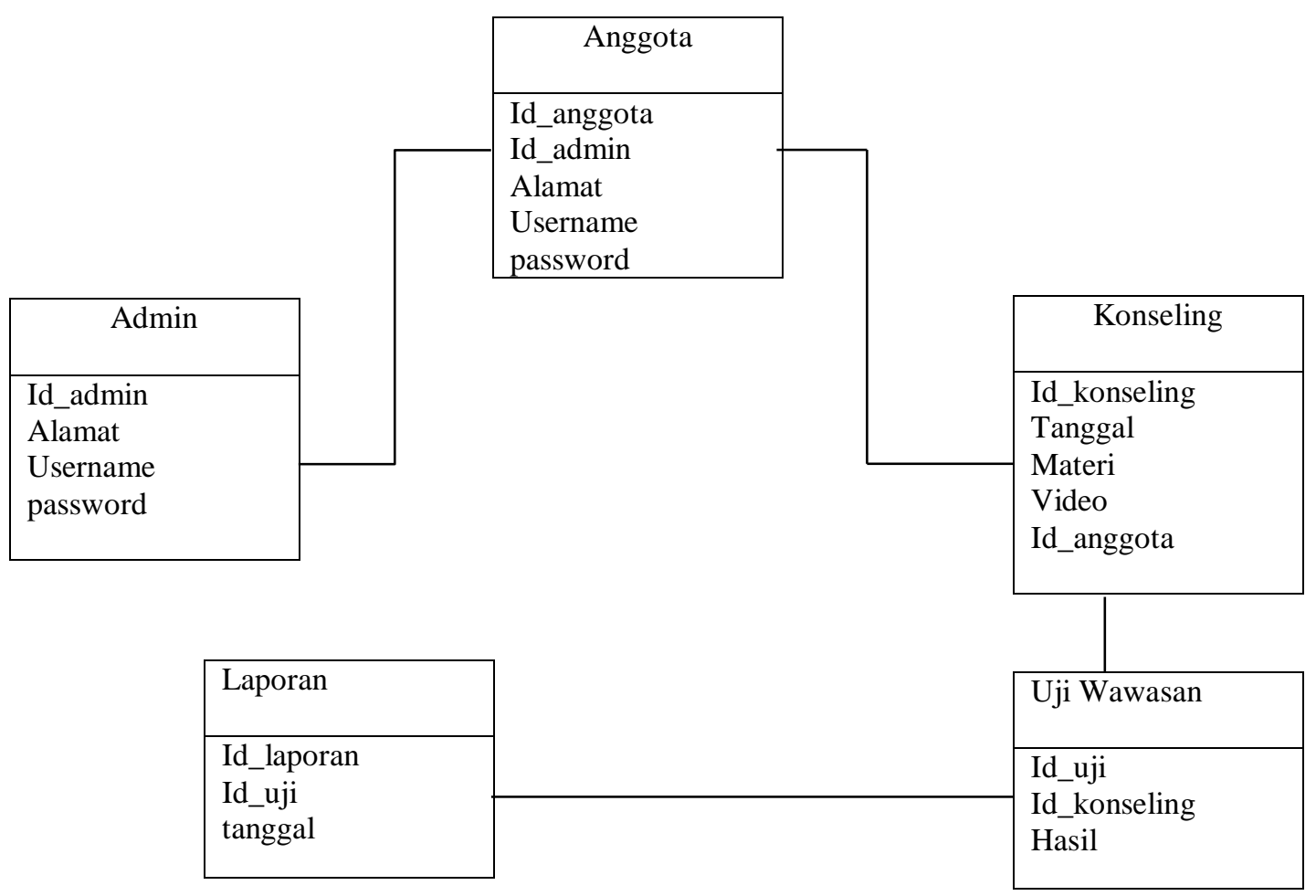

Gambar 4. Logical record structure

5. Spesifikasi File

a. Spesifikasi File Admin

Nama File

Fungsi

Akronim

Media File

Organisasi File

Akses File

Panjang Record

Field Key

Software
: File Admin

: Digunakan untuk mengelola data admin

: admin.myd

: Harddisk

: Index Sequental

: Random

: 111 Byte

: id_admin

: MySql 
P-ISSN $2580-7781$

E-ISSN 2615 - 3238

Tabel 1. Spesifikasi file admin

\begin{tabular}{cllccc}
\hline No. & Elemen Data & \multicolumn{1}{c}{ Nama Field } & Tipe & Panjang & Keterangan \\
\hline 1. & ID Admin & id_admin & Char & 6 & Primary Key \\
2. & Nama & Nama & Varchar & 20 & \\
3. & Username & Username & Varchar & 50 & \\
4. & Password & Password & Varchar & 35 & \\
\hline
\end{tabular}

b. Spesifikasi File Anggota

Nama File

Fungsi

Akronim

Media File

Organisasi File

Akses File

Panjang Record

Field Key

Software
: File Anggota

: Digunakan untuk mengelola data anggota

: anggota.myd

: Harddisk

: Index Sequental

: Random

: 80 Byte

: id_anggota

:MySql

Tabel 2. Spesifikasi file anggota

\begin{tabular}{cllccl}
\hline No. & Elemen Data & Nama Field & Tipe & Panjang & Keterangan \\
\hline 1. & ID Anggota & id_anggota & Char & 6 & Primary Key \\
2. & ID Admin & id_admin & Char & 6 & Foreign Key \\
2. Alamat & alamat & Varchar & 30 & \\
3. & Username & username & Double & 30 & \\
4. & Password & password & Double & 8 & \\
\hline
\end{tabular}

c. Spesifikasi File Konseling

Nama File

Fungsi

Akronim

Media File

Organisasi File

Akses File

Panjang Record

Field Key

Software
: File Konseling

: Digunakan untuk mengelola data konseling

: konseling.myd

: Harddisk

: Index Sequental

: Random

: 218 Byte

: id_konseling

: MySql 
P-ISSN 2580 - 7781

E-ISSN $2615-3238$

Tabel 3. Spesifikasi file konseling

\begin{tabular}{cllccc}
\hline No & Elemen Data & Nama Field & Tipe & Panjang & Keterangan \\
\hline 1. & ID Konseling & id_konseling & Char & 6 & Primary Key \\
2. & Tanggal & id_anggota & Date & 6 & \\
3. & Materi & tanggal & Varchar & 100 & \\
4. & Video & jam_selesai & Varchar & 100 & \\
5. & ID Anggota & status_jadwal & Char & 6 & Foreign Key \\
\hline
\end{tabular}

6. User Interface

a. Tampilan Halaman Utama

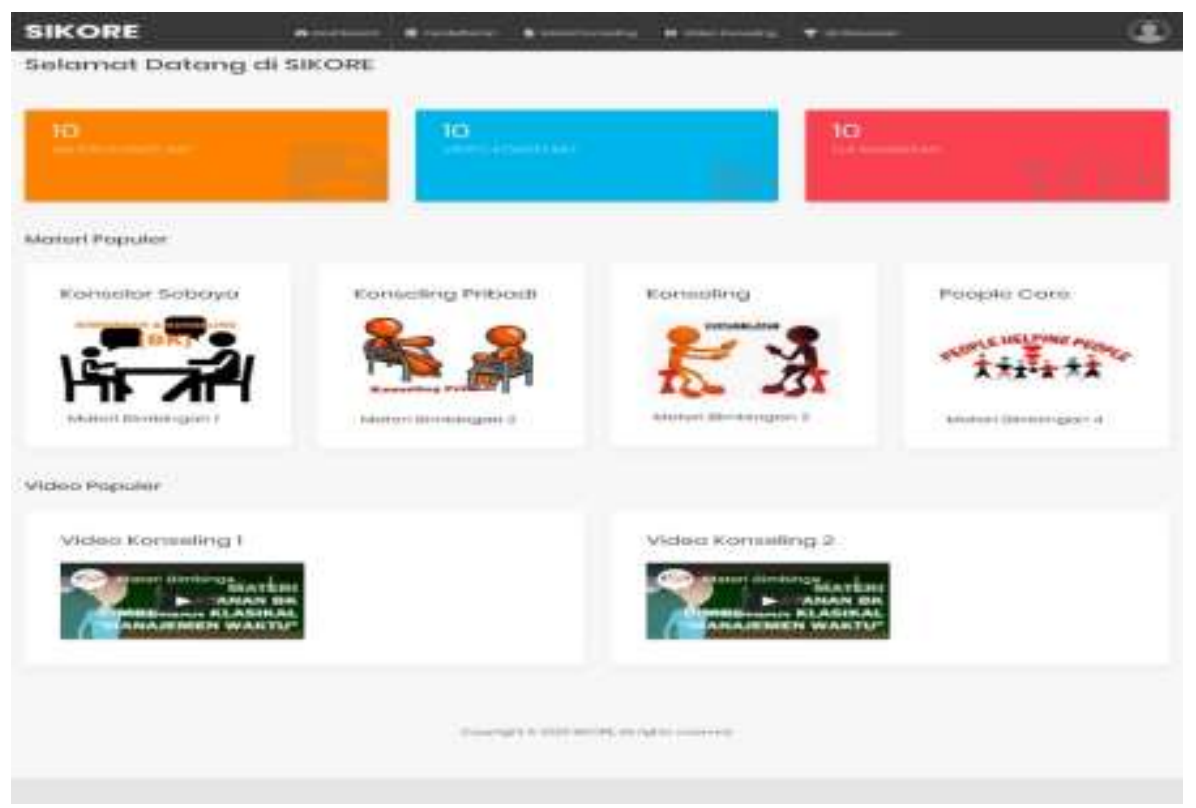

Gambar 5. Tampilan halaman utama 


\section{P-ISSN 2580 - 7781}

E-ISSN $2615-3238$

b. Tampilan Halaman Materi Konseling

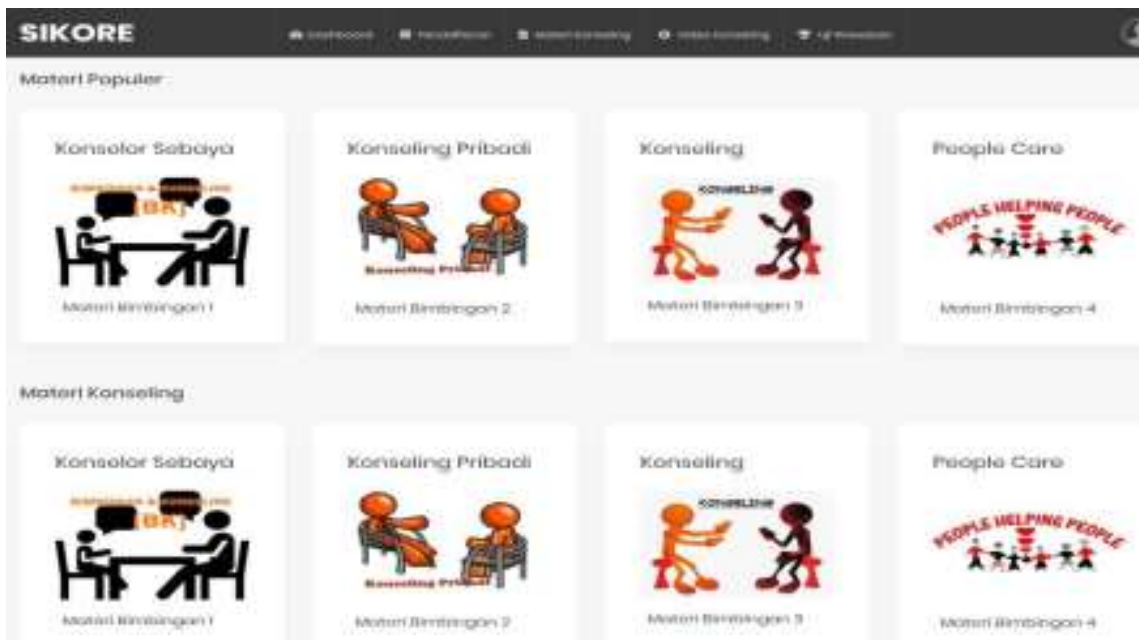

Gambar 6. Tampilan halaman materi konseling

c. Tampilan Halaman Video Konseling

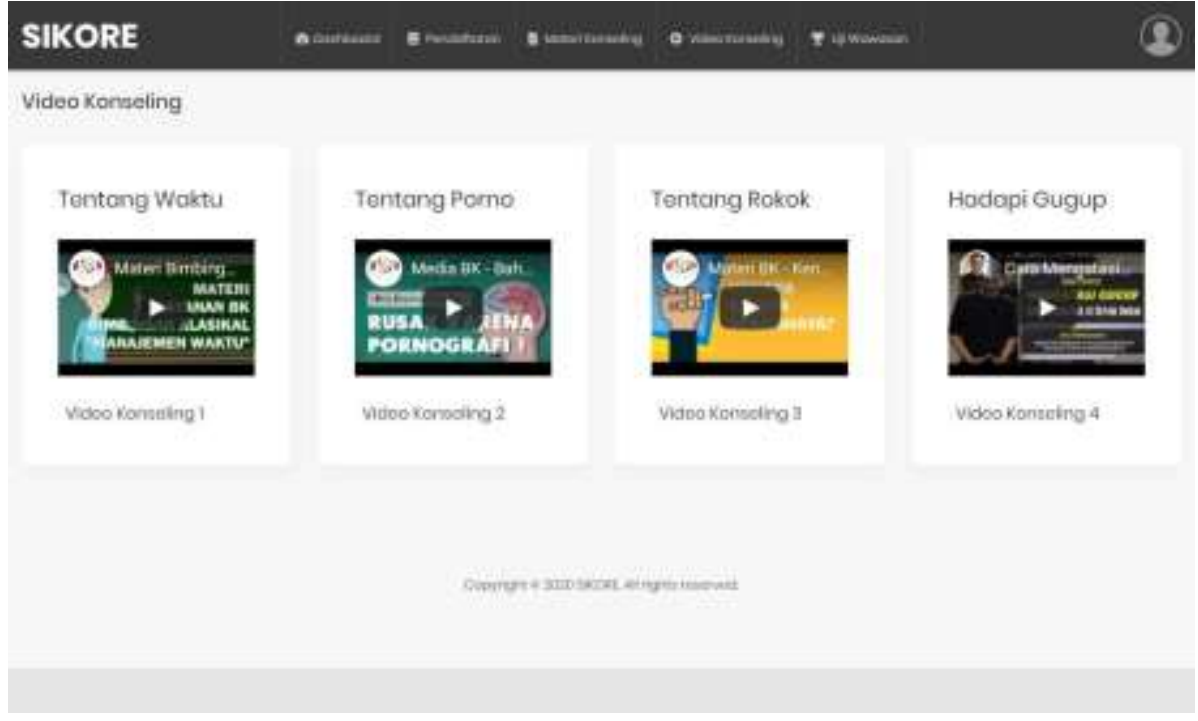

Gambar 7. Tampilan halaman video konselin 


\section{P-ISSN 2580 - 7781}

E-ISSN 2615 - 3238

d. Tampilan Dialog Uji Wawasan

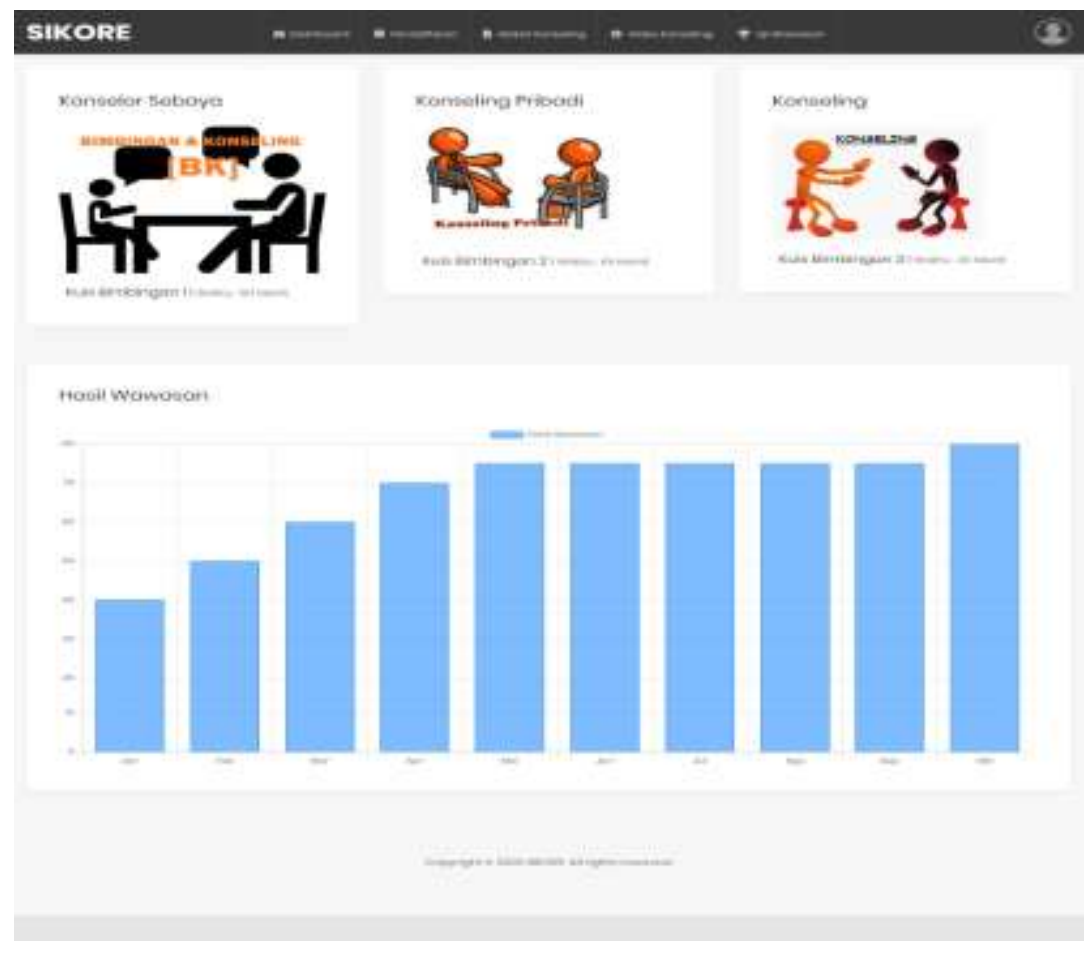

Gambar 8. Tampilan dialog uji wawasan

e. Tampilan Dialog Hasil Uji Wawasan

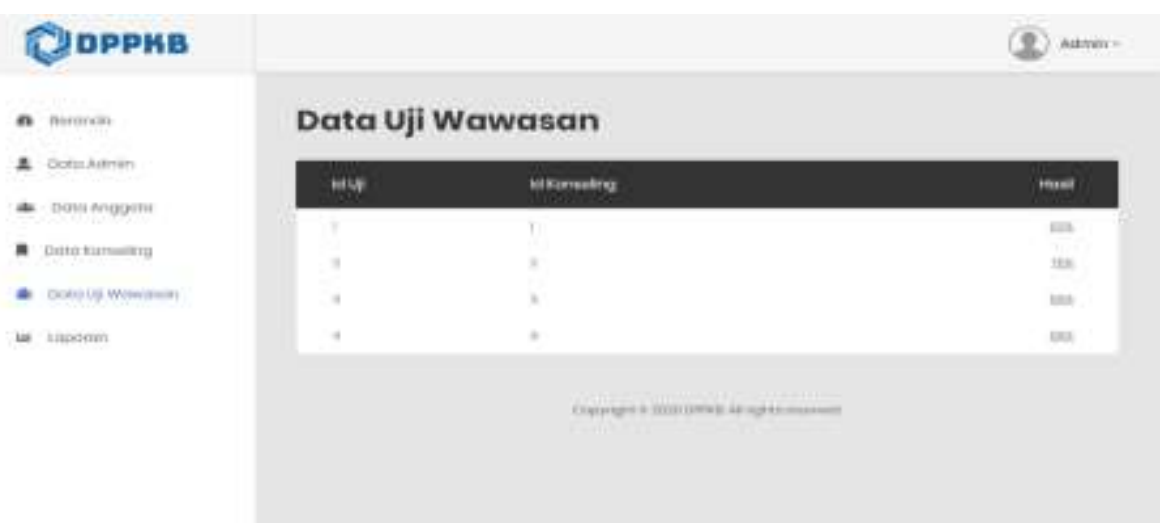

Gambar 9. Tampilan dialog hasil uji wawasan 
P-ISSN 2580 - 7781

E-ISSN 2615 - 3238

\section{KESIMPULAN}

Dalam Rancang Bangun Sistem Informasi Konseling Remaja Pada Dinas Pengendalian Penduduk Dan Keluarga Berencana maka dari itu penulis dapat mengambil kesimpulan sebagai berikut :

1. Sistem lama mengakibatkan Koordinator SATPEL per-kecamatan harus bolakbalik ke DPPKB yang tentunya memakan waktu untuk mengantarkan undangan kegiatan atau ketempat tujuan, hal tersebut tentu sangat menyita waktu.

2. Dalam proses penyampaian sosialisasi kegiatan ke beberapa sekolah dan ke berbagai tempat tersebut masih berupa surat undangan atau berupa kertas yang kemungkinan akan berceceran bahkan tidak terbaca atau hilang.

\section{SARAN}

Sesuai dengan permasalahan yang terdapat pada proses penyampaian kegiatan sosialisasi pada Bidang Pembangunan Ketahanan Keluarga (PKK) di kantor Dinas Pengendalian Penduduk dan Keluarga Berencana, (DPPKB), penulis memberikan saran sebagai berikut :

1. Diperlukannya sistem baru untuk menggantikan sistem lama yang masih manual dalam proses penyampaian kegiatan sosialisasi. Dengan sistem yang telah terkomputerisasi tentunya akan memaksimalkan proses penyampaian kegiatan sosialissai tersebut ke beberapa sekolah atau ke berbagai tempat lainnya.

2. Dengan saran dibuatnya rancangan Rancang Bangun Sistem Informasi Konseling Remaja Pada Dinas Pengendalian Penduduk Dan Keluarga Berencana ini, agar memudahkan pihak dari provinsi maupun coordinator SATPEL per-kecamatan. Karena jika adanya system yang sudah terkomputerisasi, informasi pelaksanaan konselinng remaja yang disampaikan dapat lebih mudah di terima dan tidak perlu repot untuk bolak-balik ke kantor DPPKB.

3. Disarankan bisa di online secara hosting agar bisa di akses secara online.

4. Dibackup secara berkala. 
P-ISSN 2580 - 7781

E-ISSN $2615-3238$

\section{DAFTAR PUSTAKA}

Asriati, N. (2012). Mengembangkan Karakter Peserta Didik Berbasis Kearifan Lokal melalui Pembelajaran di Sekolah. Jurnal Pendidikan Sosiologi dan Humaniora, 3(2),106-119, htp://jurnal.untan.ac.id/index.php/JPSH/article/ viewFile/3663/3670.

Anwar Sanusi, Metodologi Penelitian Bisnis,(Jakarta : Salemba Empat, 2016), h.32

Ditjen Pendas dan Menengah,2012, Membangun SMA bermutu di Tapal Batas, Direktorat Pembinaan SMA: Jakarta

Kusuma, R. S. (2018). Peran Sentral Kearifan Lokal Dalam Peningkatan Kualitas Pendidikan. PEDAGOGIK: Jurnal Pendidikan, 5(2), 228-239.

Raharjo, S. B. (2012). Evaluasi trend kualitas pendidikan di indonesia. Jurnal Penelitian dan Evaluasi Pendidikan, 16(2), 511-532.

Suti, M. (2011). Strategi peningkatan mutu di era otonomi pendidikan. Jurnal Medtek, $3(2), 1-6$.

Sinambela, L. P. (2017). Profesionalisme Dosen Dan Kualitas Pendidikan Tinggi. Jurnal Sosial dan Humaniora, 2(4).

Ishikawa, Kaoru. (2005). Pengendalian Mutu Terpadu, PT Remaja Rosdakarya, Bandung. 